\title{
Factors affecting utilization of postnatal care service in Jabitena district, Amhara region, Ethiopia
}

\author{
Yinager Gebeyehu Workineh, Desta Aregawi Hailu* \\ Department of Nursing, College of Medicine \& Health science, Arba Minch University, Arba Minch, Ethiopia
}

Email address:

workinehyinager@ymail.com (Y. G.Workineh), destahailu19@gmail.com (D. A. Hailu)

\section{To cite this article:}

Yinager Gebeyehu Workineh, Desta Aregawi Hailu. Factors Affecting Utilization of Postnatal Care Service in Amhara Region, Jabitena District, Ethiopia. Science Journal of Public Health. Vol. 2, No. 3, 2014, pp. 169-176. doi: 10.11648/j.sjph.20140203.15

\begin{abstract}
Background: Each year, 287,000 women die from complications related to pregnancy and childbirth, and about $99 \%$ of these deaths occur in developing countries. The first hours, days and weeks after childbirth are a dangerous time for both the mother and newborn infant. Post natal care prevents the great majority of maternal and child morbidity and mortality. Despite its importance, this period is generally the most neglected in developing countries. This study therefore aims to identify factors affecting PNC service utilization among child bearing age women who gave birth in the past two years in Jabitena district, Amhara region, Ethiopia. Method: Community based cross-sectional study was conducted from March to June 2013. Multistage sampling technique was employed to select the study participants. A pre-tested questionnaire was used .Bivariate and multivariate data analysis was performed using SPSS version 17.0 software. Result: In this study $20.2 \%$ mothers utilized postnatal care service. Educational status of the mother, final decision maker on health care service utilization, number of pregnancy, place of delivery and being aware of at least one postpartum obstetric danger sign were found to be significantly associated with post natal care service utilization. Conclusion: proportion of postnatal care service was very small. Educational status, women's autonomy, number of pregnancy, place of delivery and knowledge of postpartum obstetric danger sign were the factors making a difference in utilizing post natal care service. Thus, strengthening the provision of information, education and communication (IEC) was recommended.
\end{abstract}

Keywords: Postnatal Care, Predictors, Cross-Sectional Study, Amhara Region

\section{Background}

Each year, 287,000 women die from complications related to pregnancy and childbirth, and about $99 \%$ of these deaths occur in developing countries [1]. The first hours, days and weeks after childbirth are a dangerous time for both the mother and newborn infant $[2,3,4]$. Between $50 \%$ and $71 \%$ of maternal deaths happen during postpartum period, particularly in the first few hours [5]. This figure has shown great discrepancy between developed and developing countries. Maternal mortality ratio (MMR) in developing regions is 15 times (240/100,000 live births) higher than in developed regions (16/100,000live births). Sub-Saharan African countries (SSA) had the highest MMR at 500 maternal deaths per 100,000 live births [1].

Newborn health and survival is inextricably linked to the health of the mother [2,6]. Every year, four million infants die within their first month of life, representing nearly 40 percent of all deaths of under5 age children [2]. Almost all of these newborn deaths occur in developing countries, with the highest number in south Asia and the highest rates in sub-Saharan Africa [2]. In Ethiopia like many other SSA maternal and child mortality are still high. Recent estimates showed that the country still experiences of maternal, neonatal and infant mortality of 767/100,000, 37/1000, 59 per 1000 live births respectively [7].

Around $80 \%$ of maternal deaths worldwide are brought about by direct causes such as hemorrhage, infection, obstructed labor, unsafe abortion, and high blood pressure [5]. Severe obstetric bleeding is a major cause of death in both developing and developed countries. Postpartum bleeding can kill even a healthy woman within two hours, if unattended. It is the quickest of maternal killers. Moreover, preterm birth, asphyxia and severe infections contribute to two thirds of all neonatal deaths if not attended by skilled provider [3].

Appropriate post natal care (PNC) in the first hours and days following childbirth prevents the great majority of maternal and child morbidity and mortality [3]. It is 
important for both the mother and the child not only to treat complications arising from the delivery, but also to provide the women with important information on how to care for themself and their child [7].It is an opportunity for mothers and newborns to establish and maintain contact with a number of maternal and child health $(\mathrm{MCH})$ services and promote healthy behaviors such as getting proper nutrition during breastfeeding and using family planning[2].Moreover, early postnatal care is critical to promote healthy household practices such as exclusive breastfeeding that are key to the health and survival of the new born child[2].

The World Health Organization (WHO) stated that the postnatal period begins immediately after the birth of the baby and extends up to six weeks (42 days) after birth [3]. The principal objectives of PNC services are to support the mother and her family in the transition to a new family constellation, prevent, early diagnose and treat complications of the mother and infant, refer the mother and infant for specialist care when necessary, counsel on baby care, support breastfeeding, counsel on maternal nutrition, and supplementation if necessary, counsel and provide contraception service, and immunize the infant. With limited resources, contact with the health care system at least during the first twenty four hours and before the end of the first week would be the most effective strategy [8].

Despite its importance, this period is generally the most neglected in developing countries[3] and most mothers and new borns babies do not receive postnatal care services from a skilled health care provider during the critical first few days after delivery [2, 9]. In developed countries virtually all women and their infants receive PNC, even though the nature and frequency of this care varies considerably [3].However, in developing countries even the need for care and support after birth was less recognized and approximately one-third of women in sub-Saharan Africa give birth in facilities, and no more than 13 percent receive PNC within two days of delivery. Whether women deliver at home or in a facility, PNC services are often absent. Moreover, PNC services, where available, often lack essential elements of care required for the optimum health of the mother and her newborn [2]. In Ethiopia, the proportions of mothers attended PNC service are very much lower than SSA. The great majority of women (92\%) who had live birth in the preceding five years did not receive PNC service. Among women who received PNC service, $4 \%$ were examined within 4 hours of delivery, and $2 \%$ within 3-41 days of delivery. Generally, only $7 \%$ of women received PNC service within two days, as recommended [7].

Even though PNC service utilization plays a critical role in reducing maternal and new born child mortality, little is known about its determinants. Thus, understanding the factors related PNC utilization is critical for countries like Ethiopia with alarmingly high maternal mortality. This study therefore aims to identify factors affecting PNC service utilization among child bearing age women who gave birth in the past two years preceding to this survey in Funeteselam town, Amhara region, Ethiopia.

\section{Methods and Materials}

\subsection{Study Area and Period}

This study was conducted from April to May 2013 in Funeteselam town, Jabitena district. Funeteselam, the city of west Gojam zone, is found in the northern part of Amhara regional state 176 Kilometers from Bahirdar, the main city of Amhara regional state and 387 kilometers away from Addis Ababa, the capital city of Ethiopia.

This town is situated 1860 meters above sea level with a temperature range of $22-240$ c. It has one governmental hospital, one health center, one health post, eight private clinics \& four private drug venders. Moreover, nongovernmental organization such as save the children \& vision Ethiopia are available in this town providing mainly maternal and child health care services [10].

\subsection{Study Design and Population}

A quantitative research involving community based cross-sectional study was conducted among randomly selected reproductive age group of mothers who gave live births in the past two years preceding the data collection period. Mentally and/or physically incapable mothers were excluded from the study.

\subsection{Sample Size Determination and Sampling Procedure}

The minimum required sample size of this study was determined using single population proportion formula. Proportion of postnatal care service utilization [11], margin of error, confidence interval, design effect and nonresponse rate were assumed to be $45.9 \%, 5 \%, 95 \%, 1.5$ and $10 \%$, respectively.

$$
n_{i}=\frac{Z(\alpha / 2)^{2} \mathrm{P}(1-\mathrm{P})}{d^{2}}
$$

Where: $\mathrm{n}_{\mathrm{i}}=$ Sample size; $\mathrm{Z}(\alpha / 2)^{2}=$ confidence interval; $\mathrm{P}$ $=$ proportion of postnatal care utilization $(0.459$.) $; \mathrm{D}=$ marginal of error

$$
\text { Thus, } N_{i}=\frac{(1.96)^{2}(0.459)(1-0.459)}{(0.05)^{2}}=360
$$

Finally, taking $10 \%$ non-response rate and 1.5 design effect, the minimum sample size was determined to be 594 .

Funeteselam town was purposively selected as a study site by considering the health status of the mothers in the town and lack of previous researches related to maternal health care service. Multistage sampling technique was used to select the study subjects. First, all the Kebeles/the smallest administrative unit in Ethiopia were clustered in to five. Then, three Kebeles were randomly selected. Sample size was allocated proportionally to each randomly selected kebeles. Finally, frames of households were prepared for 
each kebele in consultation with local administrators. Households with a woman who gave birth in the past two years prior to this survey were selected using systematic random sampling from the existing sampling frame of households. For selecting the study participants different sampling intervals were used for each kebele. Whenever more than one eligible respondent was found in the same selected household, only one respondent was chosen by lottery method. For households with no eligible woman the immediate next household was selected and then, subsequent households were selected according to the already predetermined order.

\subsection{Data Collection Tool and Process}

Structured interviewer administered questionnaire was prepared and utilized after reviewing relevant literatures. The main contents of the questionnaire were socio demographic characteristics, obstetric history, postnatal care utilization, awareness about PNC service and quality of PNC service. The questionnaire was prepared in English and then translated to Amharic (local language). To check its consistency, it was back translated to English by an expert of both languages. After extensive evaluation, final version of the questionnaire was developed.

Twelve Nurses who were fluent in the local language (Amharic) and familiar with the local customs collected the data. One BSc Nurse was assigned to supervise the data collection process.

The training was given for both data collectors and supervisor by the principal investigator for two days. The training session included the general objective of the study, content of the questionnaire, ways how to keep confidentiality and privacy and mechanisms how to resolve when a problem arises.

\subsection{Data Quality Control}

An individual who have the ability to speak and write both English and Amharic languages translated the questionnaire. In order to identify the clarity and consistency of the questionnaire it was pretested on $10 \%$ of the sample in a similar population in one of the kebeles in Jabitena district outside the selected study area and necessary modifications such clarity and consistency of the questions and evidence based time allocation for each respondent were made accordingly. All the data collected from each respondent were checked for completeness, clarity and consistency by the principal investigator and the supervisor immediately at the end of each data collection days.

\subsection{Data Processing and Analysis}

Data were entered, coded and cleaned using SPSS version 16 software. Univariate analysis was computed for each independent variable to assess their individual proportion. Then, bivariate analysis was done to examine crude association of predictors on PNC service utilization.
Finally, by selecting eligible variables using forward logistic regression, the independent effect of predictors on postnatal care service utilization was examined. Odds ratio and $95 \% \mathrm{CI}$ were used to measure the statistical association $\mathrm{P}$ value 0.05 was used to determine the statistical significance of the tests. Finally, the results were presented in texts, tables and graphs.

\subsection{Ethical Consideration}

After it was thoroughly reviewed, ethical approval was secured from Addis Ababa University college of Health Sciences and permission to conduct the study was obtained from Jabitena district health office. Informed consent was obtained from each respondent. Participants were informed to withdraw from the study if they were not voluntary. Questionnaires were coded instead of using names as identification and hence, confidentiality was assured throughout the study.

\section{Result}

\subsection{Socio-Demographic Profile of Respondents}

A total of 596 women of reproductive age who gave live birth in the last two years prior to this survey were interviewed making a response rate of $100 \%$. Fifty four $(9.1 \%)$ of the respondents were found in the age range of 15-19 years. Regarding their educational status, majority $196(33 \%)$ of the participants attended elementary school. House wife $184(31 \%)$ followed by maid servant $145(24.4 \%)$ got higher scores concerning the occupational status of the respondents. Very few number $93(15.7 \%)$ of respondents reported that their monthly income was 500-1000 Ethiopian birr (table1).

Table 1. Socio-demographic characteristics of respondents in Funeteselam town, Amhara regional state, North West Ethiopia, 2013.

\begin{tabular}{lc}
\hline Variables & Frequency $(\%)$ \\
\hline Age at interview & \\
15-19 years & $54(9.1)$ \\
20-24years & $105(17.7)$ \\
25-29 years & $178(30)$ \\
$30-34$ years & $170(28.6)$ \\
35 and above years & $87(14.6)$ \\
Ethnicity & \\
Amhara & $443(74.6)$ \\
Tigray & $72(12.1)$ \\
Oromo & $58(9.8)$ \\
Others & $21(3.5)$ \\
Religion & \\
Orthodox & $515(86.7)$ \\
Muslim & $43(7.2)$ \\
Protestant & $32(5.4)$ \\
Others\# & $4(0.7)$ \\
Marital status & \\
Single & $90(15.1)$ \\
Married & $338(57)$ \\
Separated & $32(5.4)$ \\
Widowed & $92(15.5)$ \\
Divorced & $42(7)$ \\
Educational status of respondents & \\
\hline
\end{tabular}




\begin{tabular}{lc}
\hline Variables & Frequency (\%) \\
\hline Illiterate & $117(19.7)$ \\
Read and write & $116(19.5)$ \\
Elementary school & $196(33)$ \\
Secondary school & $107(18)$ \\
Higher institution & $58(9.8)$ \\
Occupational status of respondents & \\
House wife & $184(31)$ \\
Maid servant & $145(24.4)$ \\
Civil servant & $122(20.5)$ \\
Merchant & $96(16.2)$ \\
Student & $47(7.9)$ \\
Monthly income & \\
<500birr & $23(3.9)$ \\
500-1000birr & $93(15.7)$ \\
1000-1500birr & $148(24.9)$ \\
1500-2000birr & $190(32)$ \\
2000-2500birr & $120(20.2)$ \\
2500 birr and above & $20(3.4)$ \\
\hline
\end{tabular}

" catholic and traditional believers; "Guragie, afar

\subsection{Postnatal Care Service Utilization}

Of the total respondents, only $120(20.2 \%)$ utilized postnatal care service in health facilities (hospitals and health centers) under the supervision of skilled delivery attendant (fig1). Among PNC service users, majority 72 (60\%) commenced to utilize PNC service within four hours of delivery (table2).

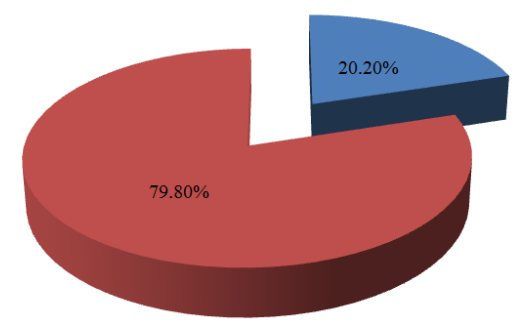

- Utilized PNC service

- Not utilized PNC service

Figure 1. The proportion of postnatal care service utilization among mothers, in Funeteselam district, Amhara regional state, Ethiopia, 2013.

\subsection{Past Obstetric History of Respondents}

Regarding their obstetric history, very few 72 (12.1\%) of the respondents got pregnant for the first time at the age of less than 19 year. Majority 260(43.8\%) of them had three children. As to mode of delivery, $558(93.8 \%)$ reported that they gave birth without instrumentation. Concerning place of last delivery, only100 (16.8\%) gave live birth in health institution with the help of skilled provider. From those who delivered at home, 113(22.9\%) had plan to utilize PNC service in health facilities with the help of trained health care provider.

As to the length of stay respondents spent in health care facilities, 91 (75.8\%) of PNC user reported waiting time was a problem for them. Little Or no knowledge 534 $(32.8 \%)$ and being healthy $446(27.4 \%)$ were the major reasons reported for not attending PNC services utilization. Regarding their decision making power, majority $483(81.3 \%)$ of the respondents reported that decision regarding PNC service utilization was made by themselves and while $111(18.7 \%)$ by husbands. As to husbands attitude, thirty two $(5.4 \%)$ of the respondents said their husbands had positive attitude towards postnatal care utilization (table2).

Table 2. Distribution of obstetric history of respondents in Funeteselam town, Amhara regional estate, North West Ethiopia, 2013.

\begin{tabular}{|c|c|}
\hline Variables & Frequency $(\%)$ \\
\hline \multicolumn{2}{|l|}{ Age at first pregnancy } \\
\hline$<19$ years & $72(12.1)$ \\
\hline $19+$ years & $522(87.9)$ \\
\hline \multicolumn{2}{|l|}{ Number of pregnancy } \\
\hline One & $110(18.5)$ \\
\hline Two & $132(22)$ \\
\hline Three & $260(43.8)$ \\
\hline Four and above & $92(15.5)$ \\
\hline \multicolumn{2}{|l|}{ Number of delivery } \\
\hline One & $183(30.8)$ \\
\hline Two & $228(38.4)$ \\
\hline Three and above & $183(30.8)$ \\
\hline \multicolumn{2}{|l|}{ Order of last delivery } \\
\hline $1 \mathrm{st}$ & $183(30.8)$ \\
\hline 2nd & $228(38.4)$ \\
\hline 3rd and above & $183(30.8)$ \\
\hline \multicolumn{2}{|l|}{ Place of Last delivery } \\
\hline Health institution & $100(16.8)$ \\
\hline Home & $494(83.2)$ \\
\hline \multicolumn{2}{|l|}{ Had cesarean section delivery } \\
\hline Yes & $61(10.3)$ \\
\hline No & $533(89.7)$ \\
\hline \multicolumn{2}{|l|}{ Had Instrumental delivery } \\
\hline Yes & $36(6.1)$ \\
\hline No & $558(93.9)$ \\
\hline \multicolumn{2}{|l|}{ Had plan for PNC utilization } \\
\hline Yes & $113(22.9)$ \\
\hline No & $381(77.1)$ \\
\hline \multicolumn{2}{|l|}{ Utilized PNC service } \\
\hline Yes & $120(20.2)$ \\
\hline No & $474(79.8)$ \\
\hline \multicolumn{2}{|c|}{ Starting time for utilization of PNC } \\
\hline Within 4 hours of delivery & $72(60)$ \\
\hline 4-23 hours of delivery & $29(24.2)$ \\
\hline Within 1-2 day of delivery & $9(7.5)$ \\
\hline Within3-46dayof delivery & $10(8.3)$ \\
\hline \multicolumn{2}{|l|}{ Number of PNC visits } \\
\hline One & $4(3.3)$ \\
\hline Two & $61(13.3)$ \\
\hline Three & $29(24.2)$ \\
\hline Four and above & $71(59.2)$ \\
\hline \multicolumn{2}{|c|}{ Waiting time was a problem $(\mathrm{N}=120)$} \\
\hline Yes & $91(75.8)$ \\
\hline No & $29(24.2)$ \\
\hline \multicolumn{2}{|c|}{ Average waiting time for utilization of PNC $(\mathrm{N}=120)$} \\
\hline$<1 \mathrm{hrs}$ & $33(27.5)$ \\
\hline $1-2 \mathrm{hrs}$ & $87(72.5)$ \\
\hline \multicolumn{2}{|c|}{ Reasons for not using PNC service } \\
\hline No/little knowledge & $534(32,8)$ \\
\hline Being healthy & $446(27.4)$ \\
\hline Being busy & $282(17.3)$ \\
\hline Far from house & $122(7.5)$ \\
\hline Long waiting time & $209(12.8)$ \\
\hline Others & $37(2.2)$ \\
\hline \multicolumn{2}{|c|}{ Decision for PNC made by her self } \\
\hline No & $483(81.3)$ \\
\hline Yes & $111(18.7)$ \\
\hline \multicolumn{2}{|c|}{ Know at least one danger signs of postpartum } \\
\hline Yes & 233(39.2) \\
\hline
\end{tabular}




\begin{tabular}{ll}
\hline Variables & Frequency $(\%)$ \\
\hline No & $361(60.8)$ \\
Know definition of PNC & \\
Yes & $183(30.8)$ \\
No & $411(69.2)$ \\
\hline
\end{tabular}

Table 3. Factors associated with post natal care service utilization among mothers in Funeteselam district, Amhara region, Northwest Ethiopia, 2013

\begin{tabular}{|c|c|c|c|c|}
\hline \multirow[t]{2}{*}{ Variables } & \multicolumn{2}{|c|}{$\begin{array}{l}\text { Utilized } \\
\text { PNC }\end{array}$} & \multirow{2}{*}{$\begin{array}{l}\text { Crude } \\
\text { OR }(95 \% \mathrm{C}\end{array}$} & \multirow{2}{*}{$\begin{array}{l}\text { Adjusted } \\
\text { OR }(95 \% \text { CI })\end{array}$} \\
\hline & Yes & No & & \\
\hline \multicolumn{5}{|c|}{ Marital status of respondents } \\
\hline Single & 8 & 34 & 1 & 1 \\
\hline Married & 71 & 267 & $1.13(0.50,2.55)$ & $2.65(0.62,11.29)$ \\
\hline Separated & 12 & 70 & $0.73(0.27,1.95)$ & $0.55(0.04,7.16)$ \\
\hline Widowed & 4 & 36 & $0.47(0.13,1.71)$ & $1.60(0.17,15.03)$ \\
\hline Divorced & 25 & 67 & $0.1 .59(0.65,3.89)$ & $0.61(0.10,3.85)$ \\
\hline \multicolumn{5}{|c|}{ Educational status of respondents } \\
\hline Illiterate & 14 & 103 & 1 & 1 \\
\hline Read and write & 18 & 98 & $1.35(0.64,2.86)$ & $0.19(0.02,2.30)$ \\
\hline $\begin{array}{l}\text { Elementary } \\
\text { school }\end{array}$ & 36 & 160 & $1.66(0.85,3.22)$ & $1.34(0.26,6.94)$ \\
\hline $\begin{array}{l}\text { Secondary } \\
\text { school }\end{array}$ & 30 & 77 & $2.85(1.42,5.77)$ & $2.69(1.45,5.97)^{*}$ \\
\hline $\begin{array}{l}\text { Higher } \\
\text { institution }\end{array}$ & 22 & 36 & $4.50(2.08,9.71)$ & $4.16(2.48,8.71)^{*}$ \\
\hline \multicolumn{5}{|c|}{ Occupational status of respondents } \\
\hline House wife & 40 & 144 & 1 & 1 \\
\hline Maid servant & 17 & 128 & $0.81(.39,1.70)$ & $0.33(0.06,1.92)$ \\
\hline Civil servant & 34 & 88 & $0.39(0.17,0.89)$ & $1.08(0.25,4.71)$ \\
\hline Merchant & 17 & 79 & $1.13(0.52,2.42)$ & $0.42(0.06,2.78)$ \\
\hline Student & 12 & 35 & $0.63(0.27,1.45)$ & $0.92(0.28,16.09)$ \\
\hline \multicolumn{5}{|c|}{ Number of pregnancy } \\
\hline One & 32 & 78 & 1 & 1 \\
\hline Two & 35 & 97 & $0.88(0.50,1.55)$ & $0.82(0.13,5.40)$ \\
\hline Three & 39 & 221 & $0.43(0.25,1.73)$ & $0.72(0.08,6.83)$ \\
\hline Four and above & 14 & 78 & $1.44(1.22,2.88)$ & $3.68(0.04,0.8) *$ \\
\hline \multicolumn{5}{|c|}{ Place of last delivery } \\
\hline Home & 29 & 465 & 1 & 1 \\
\hline $\begin{array}{l}\text { Health } \\
\text { institution }\end{array}$ & 91 & 9 & $6.22(3.80,22.25)$ & $3.6(1.79,2.32)^{* *}$ \\
\hline \multicolumn{5}{|c|}{ Had instrumental delivery } \\
\hline Yes & 15 & 103 & 1 & 1 \\
\hline No & 10 & 455 & $3.49(1.76,7.09)$ & $12.5(1.96,79.60)$ \\
\hline \multicolumn{5}{|c|}{ Had plan of PNC utilization } \\
\hline No & 16 & 365 & 1 & 1 \\
\hline Yes & 13 & 100 & $2.97(1.38,6.37)$ & $0.15(0.93,36.62)$ \\
\hline \multicolumn{5}{|c|}{ Health care decision maker for the mother } \\
\hline Others $* * *$ & 25 & 86 & 1 & 1 \\
\hline Self & 95 & 388 & $0.84(0.51,1.39)$ & $12.7(1.35,4.5)^{* *}$ \\
\hline \multicolumn{5}{|c|}{ Know at least one danger signs of postpartum } \\
\hline No & 36 & 325 & 1 & 1 \\
\hline Yes & 84 & 149 & $5.09(3.29,7.87)$ & $3.7(1.09,12.7)^{* *}$ \\
\hline \multicolumn{5}{|c|}{ Perceived long waiting time } \\
\hline No & 63 & 32 & 1 & 1 \\
\hline Yes & 57 & 152 & $1.92(1.28,2.88)$ & $3.91(1.30,1.71)^{*}$ \\
\hline
\end{tabular}

*Statistically significant at $\mathrm{p}<0.05,{ }^{* *}$ statistically significant at $\mathrm{p}<0.00$; *** Husband, other family members, Mother

\subsection{Factors Associated with Inter Birth Interval}

In multivariate logistic regression analysis, educational status of the mother, final decision maker on health care service utilization, number of pregnancy, place of delivery and being aware of at least one postpartum obstetric danger sign were found to be significantly associated with post natal care service utilization (table3).

Level of education showed strong statistical association with postnatal care service utilization. Mothers who attended secondary school were about 4 times $(\mathrm{AOR}=4.16$, $95 \% \mathrm{CL}:(2.48,8.71)$ more likely to utilize postnatal care service than illiterate women. Similarly, the odds of having four and above children decreased the chance of utilizing postnatal care service by about four fold (AOR=3.680, 95\% $\mathrm{CI}:(0.04,0.8)$ more likely than having one pregnancy. Place of delivery has also been an important predictor of postnatal care service utilization. Mothers who gave birth their last child in health institutions were about 4 times (AOR: 3.6, 95\%CI: $[1.79,2.32]$ ) more likely to utilize postnatal care service utilization.

Postnatal care service utilization also increased with increasing decision making power of mothers. Mother who were autonomous to make health care decision by themselves were about 13 time more likely to utilize postnatal care service than those whose health care decision was made by others(AOR:12.7,95\%CI:[1.35, 4.5]). The probability of postnatal care service utilization was highly associated with level of knowledge of postpartum obstetric danger signs. Mothers who had knowledge of at least one postpartum obstetric danger sign were about 4 times (AOR: $3.7,95 \% \mathrm{CI}$ : $[1.09,12.7])$ more likely to utilize postnatal care service than those who failed to mention any of the obstetric danger signs.

\section{Discussion}

This community based cross-sectional study with the objective of the assessment of factors affecting utilization of postnatal care services was conducted in Jabitena district, Amhara regional state, North West Ethiopia. It assessed the level of utilization and the exposure variables impacting postnatal care service utilization.

Evidence from the present study indicated that postnatal care service utilization was $20.2 \%$. This was significantly higher than the previous report by EDHS, Koblinsky, Mekonnen, and Araya [7, 12, 13, 14]. This may be attributed to the time difference that there could be improvement in accessing and utilizing health care service through time. This variation can also be attributed to studies by Arya and Koblinsky were conducted in the rural areas unlike to our study.

Among the socio demographic factors, the key predictor for PNC utilization in this study was educational status of the respondents. Participants whose level of education was secondary school and above showed better utilization of PNC service as compared to illiterate women. This result is 
similar with evidence from study conducted in Ethiopia, Indonesia, Uganda, and India [, 13, 14, 15, 16, 17, 18]. This could be explained by the fact that education has a valuable input in enhancing female autonomy and help women develop greater confidence and capability to make decisions about their own health. Thus, literate women seek out higher quality health services and have greater ability to use health care inputs that offer better health outcomes.

The other major factor predicting postnatal care service utilization was place of delivery. Mothers who delivered their last baby in health institution utilized PNC services more likely when compared with those who delivered at home. This finding is nearly similar with evidence from India (19), demographic health survey result in developing countries [20], and Nepal [21]. This strong positive association of PNC services utilization with place of delivery can be attributed to the fact that women who gave their last birth in health institution have greater opportunity to get exposed to health education related to PNC services at the time of delivery and thus get access to learn about the types, benefits and availabilities of PNC services during their stay in the health institutions.

As to the final decision maker on PNC service utilization, mothers who decided by themselves utilized PNC services more likely as compared to those whose health care decision is made by others. This evidence is in line with similar study conducted in Democratic republic of Congo, Mali, and Uganda [22, 23, 17]. This can be due to the autonomy of the women to take any action at any time to their health related issues. The other possible reason may be autonomous women can contact with the health professionals, and attend maternal related conferences without any interferences, and develop level of awareness about maternal health services, and then they started to use it.

Knowledge of postpartum obstetric danger signs was also found to be strong predictor of PNC utilization. Mothers who were knowledgeable to for at least one postpartum obstetric danger sign were more likely to utilize PNC service as compared to those who did not spontaneously mentioned any postpartum obstetric danger sign. This result is similar with the study conducted in Nepal, and Uganda [21, 17]. This can be explained by the fact that awareness of obstetric danger signs is an important factor in motivating women and their families to attend health care service at the earliest opportunity with the intention of prevention, early detection and getting managed their obstetric danger signs.

Birth order is another obstetric factor found to be significantly affecting the use of postnatal care service. This finding is in agreement with evidence from study conducted among mothers in rural Nepal [24] .The probability of utilizing postnatal care was decreased in mothers who got pregnant for four and above than Primi gravida women. As the number of pregnancy increases the chance of giving birth in health institution also increased implying that mothers seek modern obstetric care for their first pregnancy than for the subsequent pregnancies because they believe that they are at risk of developing obstetric complication.

\subsection{Limitation}

Despite the fact that the necessary endeavors were made to minimize or avoid the possible shortcomings of this study, the result should be interpreted in the light of the following unavoidable limitations. This study utilized cross sectional study design which made the findings impossible to establish causal relationship between the outcome and exposure variables.

Moreover, the source of the data for this study was based on the self-report of respondents, and provided no validation of obtained information with any objective source such as health facility cards. However, it is logical to assume that biases are less likely as respondents were well informed about the importance of giving accurate responses and also assured the confidentiality of their responses. Finally, recall bias was more likely since women were asked for events which have already happened within the past two years prior to this study despite the consideration of recent births.

\section{Conclusion and Recommendations}

This study was conducted to assess factors associated with postnatal care service utilization among mothers who gave birth in the past two years prior to this survey. The finding of this study revealed that level of post natal care service utilization is still alarmingly limited even though relatively higher results were registered as compared to the previous evidence.

Educational status of the mother, final decision making power on health care service utilization, number of pregnancy, place of delivery and being aware of at least one postpartum obstetric danger sign were found to be significantly associated with post natal care service utilization.

Based on the findings of this study, the following recommendations were made. This study showed that significant proportion of the mothers were not aware of postpartum obstetric danger signs. Therefore, the $\mathrm{MOH}$, and other health development stalk holders working in the area of maternal health should strengthen provision of information, education and communication. Moreover, as women's education is an important factor to promote institutional delivery, policy should also focus on encouraging women to pursue education to beyond the primary school level. Furthermore, women should also be encouraged to optimize their ability to make informed decisions about their own health care service utilization. Finally, research with robust analytical studies is recommended to substantiate this finding for more generalizability. 


\section{Abbreviations}

EDHS: Ethiopian Demographic and Health Survey, PNC: postnatal care, MDG: Millennium Development Goals, WHO: World Health Organization.

\section{Competing Interests}

The authors declare that they have no competing interests.

\section{Acknowledgements}

We would like to thank Addis Ababa University for financial assistance. We are also grateful to Jabitena district health office, supervisors, data collectors and study participants for their assistance and cooperation during the study.

\section{Authors' Contributions}

YW designed the study, participated in the data collection, performed analysis and interpretation of data and drafted the paper and participated in preparing all versions of the manuscript. DH assisted in the design and development of the proposal, participated in data collection, analysis and revised subsequent drafts of the paper. Both authors read and approved the final manuscript.

\section{References}

[1] Maternal mortality estimation interagency Group (MMEIG). Trends in maternal mortality 1990 to 2010: WHO, UNICEF, UNFPA and World Bank estimates: Switzerland; World Health Organization; 2010.Availableat: http:// www. unfpa. org/webdav/site/global/shared/documents/publications/2012 / pdf.

[2] Save the children. Postnatal Care: A Critical Opportunity to Save Mothers and Newborns. Washington, DC; population reference bureau:2007.Available at: http://www.prb.org/ pdf07/snl_pncbrieffinal.pdf-Postnatal Care:

[3] World health organizations. Technical Consultation on Postpartum and Postnatal Care: Department of making pregnancy safer; Switzerland; World Health Organization; 2008:Available at: http://whqlibdoc.who.int/hq/2010/ WHO _MPS_10.03_eng.pdf

[4] State of Victoria. Postnatal Care Program Guidelines for Victorian Health Services: Victoria: State of victory department of health; 2012.Available at: http://docs.health. vic.gov.au/docs/doc/715A53A28AA4E8CACA257ACC006 D257E/\$FILE/121022\%20Postnatal\%20care\%20guidelines _web.pdf

[5] World health organization. Make every mother and child count. Switzerland: World Health Organization; 2005. Available at: http://www.who.int/whr/ 2005/pdf.

[6] Federal Democratic Republic of Ethiopia, MOH. Health Sector Development Programme IV2010/11 - 2014/15. 2010.
[7] Central Statistical Agency. Ethiopia Demographic and Health Survey: Addis Ababa: Central statistical agency; 2011.

[8] Catalyst Consortium. Key Elements of Postpartum Care at the Community Level Based on WHO Guidelines. Available at:http://www.pathfinder.org/publications-tools/pdfs/ CATALYST-Key-Elements-of-Postpartum-Care-at-theCommunity-Level-Based-on-WHO-Guidelines.pdf

[9] United Nations Children's Fund (UNICEF). Maternal and Newborn Health where do we stand: New York ;Unicef; 2009.Available at: http://www.unicef.org/sowc 09/ docs/ SOWC09-FullReport-EN.pdf

[10] Jabitena district Health office: Report of the district Health department; 2011

[11] Federal Democratic Republic of Ethiopia, MOH. Health and Health related indicators: Policy planning directorate. Ethiopia: FMOH; 2011.

[12] Koblinsky M. Reducing maternal mortality and increasing use of skilled birth attendance .Ethiopian Journal of Reproductive Health 2012; 4(1), 9-10:

[13] Mekonnen, Yared, and Asnaketch M. Utilization of Maternal Health Care Services in Ethiopia. Calverton, Maryland, USA: ORC Macro, 2002.

[14] Araya M., Mark S., \& Yohannes K. The role of health extension workers in improving utilization of maternal health services. BMC Health Services Research 2012; 12(35), 6-7.

[15] Worku et al.: Factors affecting utilization of skilled maternal care in Northwest Ethiopia: a multilevel analysis. BMC International Health and Human Rights 201313:20

[16] Titaley CR., Dibley MJ., \& Roberts CL. Factors associated with non-utilization of postnatal care services in Indonesia. J Epidemiol CommunityHealth2009;63:827-831.doi:10.1136 / jech. 2008.081604

[17] Annet N. Factors influencing utilization of postnatal services. University of the Western Cape; 2004. Available at: http:etd. uwc.ac.za/usrfiles/modules/ etd/.../ etd_ init_ 6986 _1174047746.pdf.

[18] Digambar A., \& Sahoo H. Factors influencing utilization of maternal health care services in uttarakhand ,India: Etho Med 2012; 5(3), 209-216.

[19] Jat R., Nawi Ng., and Sebastian S. Factors affecting the use of maternal health services. Madhya Pradesh state in India. International Journal for Equity in Health 2012; 10(59), 7-9.

[20] Demographic and health survey comparative reports of 26 countries. Level \& trends in the use of maternal health services in developing countries. USAID ICF Macro; 2011

[21] Dhakal et al.: Utilization of postnatal care among rural women. BMC Pregnancy and Childbirth 2007; 7(19), 3-6.

[22] Ntambue M., Malonga K., Dramaix W., and Donnen P. Determinants of maternal health services utilization in Democratic Republic of Congo. BMC Pregnancy and Childbirth 2012; 12(66), 6-7.

[23] Sakala B., Kazembe A. Factors influencing the utilization of postnatal care at one week and six weeks among mothers at Zomba Central Hospital in Malawi. Evidence Based Midwifery 2011: 9(4): 113-136. 
[24] Sulochana D., Glyn N., Padam P., Edwin R.,Teijlingen, Jane S., and Amalraj R. .Utilization of postnatal care among rural women in Nepal. BMC Pregnancy and Childbirth2007, 7:19 doi:10.1186/1471-2393-7-19 